\title{
IVF Sonrası Canlı Doğumla Sonuçlanan Heterotopik Gebelik; Olgu Sunumu
}

\section{Heterotopic Pregnancy Resulting in a Live Birth After IVF; Case Report}

Fedi Ercan ${ }^{1}$,

Osman Balcı',

Cemre Alan ${ }^{1}$,

Mehmet Çolakoğlu ${ }^{1}$

${ }^{1}$ Necmettin Erbakan Üniversitesi Tıp

Fakültesi, Kadın Hastalıkları ve Doğum

Anabilim Dalı, Konya, Türkiye

Geliş Tarihi/Received: 13 Ocak 2017

Kabul Tarihi/Accepted: 25 Kasım 2017

Yazışma Adresi: Fedi Ercan

Necmettin Erbakan Üniversitesi Tıp Fakültesi, Kadın Hastalıkları ve Doğum Anabilim Dalı,

Konya, Türkiye

e-posta: fediercan@gmail.com

ORCID

Fedi Ercan

https://orcid.org/0000-0003-2175-5405

\begin{abstract}
Öz
Heterotopik gebelik, intrauterin ve ektopik gebeliğin aynı anda olmasıdır. Yardımcı üreme tekniklerinin (YÜT) uygulama sıklığı arttıkça heterotopik gebeliklerin görülme sıklığı \%1-3' e kadar yükselmiştir. Heterotopik gebelik nadir bir durum olduğundan standart bir takip ya da tedavi yöntemi yoktur. Genel olarak metotreksat, RU 486 (Mifepriston) ve prostaglandinler intrauterin gebeliğin devam ettirilmesi istendiğinde embriyo üzerine potansiyel teratojen etkileri olması nedeniyle kullanılmamaktadır. Burada ektopik gebeliğin cerrahi olarak tedavi edildiği ve intrauterin gebeliğin miada ulaşıp sağlıklı bir infantın doğduğu bir heterotopik gebelik olgusu sunulmuştur.

Anahtar Kelimeler: Heterotopik gebelik, yardımcı üreme teknikleri

\section{Abstract}

Heterotopic pregnancy is a condition in which intra- and extrauterine pregnancies occur at the same time. However in the last decades there has been a significant increase of heterotopic pregnancy as high as $\% 1-3$, this raised frequency has been attributed to the extended use of assisted reproductive technologies. Because it is a rare condition,there is no standart management or treatment method for heterotopic pregnancy. Usually methotrexate, RU 486 (Mifepristone) and prostaglandins aren't used if intrauterine pregnancy wanted to persist, because of their potantial teratogenic effects on embryo. Here we present a case with heterotopic pregnancy who were treated by surgery for ectopic pregnancy and intrauterine pregnancy ended with labour of a healthy infant in term.
\end{abstract}

Keywords: Heterotopic pregnancy, assisted reproductive technologies

\section{GíRiş}

Heterotopik gebelik, intrauterin ve ektopik gebeliğin aynı anda olmasıdır (1). İnsidansı 1/100 ile 1/30000 gebelik arasında değişmektedir. Yardımcı üreme tekniklerinin (YÜT) uygulama sıklığı arttıkça heterotopik gebeliklerin görülme sıklığı \%1-3' e kadar yükselmiştir (2). Heterotopik gebelik nadir bir durum olduğundan standart bir takip ya da tedavi yöntemi yoktur. Bilinen klasik cerrahi yaklaşımlar dışında literatürde başka tedavi yöntemleri de tanımlanmıştır. Küçük olgu serilerini içeren çalışmalarda ultrasonografi rehberliğinde lokal metotreksat, RU 486 (Mifepriston), prostaglandinler veya potasyum klorid enjeksiyonu ya da heterotopik gebeliğin transvaginal yoldan aspirasyonu sonrasında kese içine hiperosmolar glukoz enjeksiyonu gibi yöntemler de bildirilmiştir $(3,4)$. Ancak genel olarak MTX, RU 486 ve prostaglandinler intrauterin gebeliğin devam ettirilmesi istendiğinde embriyo üzerine potansiyel teratojen etkileri olması nedeniyle kullanılmamaktadır.

Burada ektopik gebeliğin cerrahi olarak tedavi edildiği ve intrauterin gebeliğin miada ulaşıp sağlıklı bir infantın sezeryan ile doğurtulduğu bir heterotopik gebelik olgusu sunulmuştur.

\section{OLGU}

Otuz yedi yaşında, 4 yıllık evli primer infertil hasta çocuk istemi nedeniyle kliniğimize başvurdu. Adetleri düzenli ancak ağrılı geçen hastanın öyküsünde dikkati çeken başka bir özellik yoktu. Jinekolojik transvajinal ultrasonografide her iki overde 5'ten fazla antral folikül gözlemlendi. Yapılan histerosalpingografide uterin kavite ve her iki tubal patens normal izlendi. Vücut kitle indeksi $28 \mathrm{~kg} / \mathrm{m}^{2}$ olan hastanın bazal hormon profili normaldi. Eşinin spermiyogramında ciddi oligoastenoteratozoospermi görülen hasta bunun üzerine yardımcı üreme teknikleri (YÜT) ile tedavi programına alındı. Daha önce 2 kez YÜT uygulanan 
ve başarısız olan hastanın bu 3.YÜT denemesidir.

Hastaya bir önceki siklusun 21.gününde $\mathrm{GnRH}$ analoğu 10 IU / gün (Lucrin $®$ / Abbott, Fransa) başlandı ve bu tedaviye $\beta$-hCG enjeksiyon gününe kadar devam edildi. Takiben adetin 3. gününde rekombinant FSH 150 IU / gün (Puregon® / Organon, Hollanda) ile ovarian stimülasyona geçildi. En az bir lider folikül boyutu $18-20 \mathrm{~mm}$ çapına ulaşınca, 10 000 IU HCG (Pregnyl® / Organon Shering Plough) uygulandı. Yaklaşık 36 saat sonra transvajinal ultrason rehberliğinde oosit pick-up gerçekleştirildi. Toplam 12 oosit toplandı ve tüm oositlere ICSI uygulandı. Oosit pick-up sonrası 3.günde, 1 adet grade 2 ve 1 adet grade 1 embriyo transfer edildi. Luteal faz desteği günlük vajinal progesteron jel (Crinone\% 8-Serono/ Merk Laboratories) ile sağlandı. Gebelik testi transfer sonrası 12.günde pozitif olan hastanın gebeliği 18.günde ultrasonografik olarak da teyit edildi.

Hasta transferden 4 hafta sonra ciddi kasık ağrısı ile acil servise başvurdu. Tansiyon arteriyel 80/50 $\mathrm{mmHg}$ ve nabız 114 atım/dakika (ritmik, filiform) olarak alındı. Yapılan jinekolojik muayenede uterus 2 aylık gebelik iriliğinde, adneksler bilateral hassas idi. Vajinal kanaması yoktu. Abdomen muayenesinde ise periton irritasyon bulguları, defans ve rebound hassasiyet mevcuttu. Hemoglobin değeri $7,9 \mathrm{gr} /$ $\mathrm{dL}$, hematokrit \% 28.9 ve biyokimyasal değerleri normal sınırlarda idi. Transvajinal ultrasonografide intrauterin 6 hafta 5 günlük fetal kardiyak aktivite izlenen gebelik, Douglas'ta 95x49 mm, dalak lojunda $90 \times 70 \mathrm{~mm}$ ve sol parakolik alanda $75 \times 40$ mm sıvı kolleksiyonu gözlemlendi. Ancak adneksiyal alanlarda stimüle overler dışında başka bir bulguya rastlanmadı. Hastanın durumu hemodinamik olarak stabil olmadığından laparoskopinin uygun olmadığı düşünülerek laparotomi kararı verildi. Ameliyatta sağ tuba kaynaklı rüptüre ektopik gebelik izlenen ve yaklaşık batın içi $2000 \mathrm{cc}$ defibrine kan aspire edilen olguya sağ salpenjektomi uygulandı. Ameliyat sonrası 2.günde yapılan ultrasonografide intrauterin 7 haftalık gebeliğin sorunsuz devam ettiği gözlendi. Ameliyat sonrası 4.günde hasta taburcu edildi. İntrauterin gebelik takibi sorunsuz devam eden hasta 39. haftada makat prezantasyon nedeni ile sezaryenle 3200 gr sağlıklı erkek bebek doğurdu. Ameliyat sonrası problem görülmeyen hasta postoperatif 2.günde taburcu edildi.

\section{TARTIŞMA}

Spontan sikluslarda heterotopik gebelik insidansı düşük olsa da yardımcı üreme teknikleri ile oluşan gebeliklerde insidans 10 ila 100 kat artış göstermektedir (1). Heterotopik gebelik tubal, servikal, ovaryan, kornual veya abdominal gebeliğe eşlik eden intrauterin gebelik şeklinde görülebilmektedir ve predispozan faktörler ektopik gebelik ile benzerdir (2). Heterotopik gebelik için yardımcı üreme tekniklerinin hazırladığı zemin transfer edilen embriyo sayısının artması ile (ikiden fazla olması ile) daha da belirginleşmektedir (5). Görüntüleme teknikleri günümüzde oldukça gelişmiş olmasına karşın, bu olguda da görüldüğü şekilde heterotopik gebelik hastaların büyük kısmında akut batın tablosuyla tanı almaktadır. İntrauterin gebeliğin izlenmiş olması birçok olguda heterotopik gebelik tanısını geciktirmektedir (6). Ve bu hastalarda genellikle ilk tanı düşük tehdidi olmaktadır. Ancak, YÜT ya da ovulasyon indüksiyonu gibi bir faktör söz konusu ise heterotopik gebeliği özellikle düşünmek gereklidir.

Tanıda ß-HCG kullanımı, intrauterin gebeliğin varlığı sebebiyle sınırlıdır. Transvajinal ultrason tanı açısından oldukça önemlidir. Ancak birçok olgu yalnız intrauterin gebeliğin görülmesi, ekstrauterin gebeliğin görülememesi nedenleriyle gözden kaçmakta ve tanı gecikmektedir. Bu olguda da 6 . gebelik haftasında kasık ağrısı ve ultrasonografide batın içi serbest sıvı gözlenmesi üzerine yapılan cerrahi eksplorasyon ile ektopik gebelik tanısı konulmuş ve tedavisi sağlamıştır. Özellikle yardımcı üreme tekniklerinin uygulandığı sikluslardan sonra gelişen gebeliklerde adneksiyal yapıların yapılan tedaviye sekonder olarak kompleks gözükmesi nedeniyle tanıda çok daha dikkatli olmak gerekir. Bu gebeliklerin erken teşhis ve uygun tedavisi, hastanın ve devam etmekte olan gebeliğin prognozu için oldukça önemlidir. Yardımcı üreme teknikleri uygulanan hastalarda tedaviye sekonder olarak hiperstimüle olmuş overlerin torsiyonu da klinik olarak heterotopik gebelik tablosunu taklit edebilir. Zaman zaman görüntüleme yöntemleri ile her iki durum ayırımı yapılamadığından teşhisi için cerrahi eksplorasyon son seçenek olabilir.

Heterotopik gebelik nadir bir durum olduğundan standart bir takip ya da tedavi yöntemi yoktur. Yaygın hemoperitoneum varlığında, bu hastada da yapıldığı şekilde cerrahi tedavi tek seçenektir. Ultrasonografi eşliğinde intakt tubal ektopik gebelik materyaline potasyum klorür, RU 486 (Mifepriston), prostaglandinler veya potasyum klorid $(\mathrm{KCl})$ enjeksiyonu yapılabilmektedir. Ancak bu ajanların potansiyel olarak devam etmekte olan intrauterin gebeliğe olumsuz etkileri söz konusudur. İntrauterin gebeliğin devamı istenmiyor ise sistemik metotreksat 
tedavisi diğer bir seçenek olabilir. Cerrahi gereken olgularda intrauterin gebeliğin devamı isteniyorsa uterusa minimal travma ve kısa-yüzeyel anestezi ile operasyon tamamlanmalıdır. Ameliyat sırasında özellikle korpus luteum içeren overin kan akımının korunmasına dikkat edilmesi gerekmektedir. Özellikle kullanılan yardımcı üreme teknikleri uygulamalarına sekonder olarak hiperstimüle olan overlerin manipülasyonu sırasında travmaya hassas ve kanamaya müsait durumu nedeniyle dikkatli olunmalıdır.

Cerrahi tercihte akılda tutulması gereken bir diğer önemli nokta kornual, servikal ve sezaryen skarı gibi tuba dışı lokalizasyondaki heterotopik gebeliklerde müdahale sırasında histerektomi gerektirebilecek kanama olabileceğiyönünden hastadan bilgilendirilmiş onamının alınmasıdır. Heterotopik gebeliğin intrauterin komponenti, normal intrauterin gebelik ile karşılaştırıldığında artmış düşükle sonuçlanma riski taşır (7).

Sonuç olarak; spontan heterotopik gebelik oldukça ender görülmesine rağmen kasık ağrısı ve peritoneal irritasyon bulguları ile başvuran ilk trimester gebeliklerde özellikle de yardımcı üreme teknikleri ile gebelik elde edilmişse, heterotopik gebelik ayırıcı tanısı düşünülmelidir. Ultrasonografi ile intrauterin gebelik görülmüş olsa dahi adneksler ektopik gebelik odağı konusunda ayrıntılı olarak taranmalıdır.
Çıkar Çatışması: Çalışmada herhangi bir çıkar çatışması yoktur.

Finansal Çıkar Çatışması: Çalışmada herhangi bir finansal çıkar çatışması yoktur.

Yazışma Adresi: Fedi Ercan, Necmettin Erbakan Üniversitesi Meram Tıp Fakültesi, Kadın Hastalıkları ve Doğum Anabilim Dalı, Konya, Türkiye

Tel: +905058955309

e-mail: fediercan@gmail.com

\section{KAYNAKLAR}

1. Schroeppel TJ, Kothari SN. Heterotopic pregnancy: A rare cause of hemoperitoneum and the acute abdomen. Arch Gynecol Obstet 2006;274:138-40.

2. Strandell A, Thorburn J, Hamberger L. Risk factors for ectopic pregnancy in assisted reproduction. Fertil Steril 1999;71:2826.

3. Fernandez $\mathrm{H}$, Lelaidier $\mathrm{C}$, Doumerc $\mathrm{S}$, et al. Nonsurgical treatment of heterotopic pregnancy. A report of six cases. Fertil Steril 1993;60:428-32.

4. Goldberg JM, Bedaiwy MA. Transvaginal local injection of hyperosmolar glucose for the treatment of heterotopic pregnancies. Obstet Gynecol 2006;107:509-10.

5. Talbot K, Simpson R, Price N, et al. Heterotopic pregnancy. J Obstet Gynaecol 2011;31:7-12.

6. Ceci O, Caradonna F, Loizzi P, et al. Ultrasound diagnosis of heterotopic pregnancy with viable fetuses. Eur J Obstet Gynecol Reprod Biol 1993;52:229-31.

7. Clayton HB, Schieve LA, Peterson HB, et al. A comparison of heterotopic and intrauterine-only pregnancy outcomes after assisted reproductive technologies in the United States from 1999 to 2002. Fertil Steril 2007;87:303-9. 